\title{
À votre santé !
}

Dominique Labie, Pascal Ferré

> Vieillir en bonne santé est une des obsessions de notre société confrontée en particulier aux excès alimentaires aboutissant à l'obésité et à ses complications, alors que la restriction calorique s'accompagne dans de nombreux organismes, levures, drosophiles, mammifères d'une augmentation de la longévité. Chez la levure et la drosophile, on a pu rattacher les effets de la restriction alimentaire à la présence d'une désacétylase NAD ${ }^{+}$ dépendante de la famille sirtuine/Sir2 [1]. En désacétylant des protéines spécifiques, les sirtuines modifient leur activité fonctionnelle. Activée par un environnement nutritionnel défavorable, cette désacétylase met en route des processus cellulaires qui permettent de prolonger l'existence en attendant des jours meilleurs. Les gènes codant des sirtuines existent chez les mammifères, et SIRTI a des effets métaboliques contribuant aux adaptations observées lors de la restriction calorique. Est-il concevable de mettre en route artificiellement ce programme, et de vivre mieux et plus longtemps? Deux équipes, I'une américaine et l'autre française, viennent d'étudier cette possibilité chez la souris en utilisant un polyphénol activateur de SIRTl, le resvératrol [2, $3]$. Les résultats de ces deux études sont dans l'ensemble concordants et complémentaires. Des souris soumises à un régime à haute densité calorique développent une obésité, une insulino-résistance et vivent moins longtemps que leurs congénères aux ingérés plus modestes. La prise journalière de resvératrol entraîne un allongement de la durée de vie des souris soumises au régime hyper- calorique, réduit leur résistance à l'insuline, améliore leurs fonctions motrices et pour les doses les plus élevées, diminue leur prise de poids. Ce phénotype est concomitant d'une augmentation du potentiel oxydatif mitochondrial (en particulier dans les muscles et le tissu adipeux brun) qui pourrait être la conséquence d'une désacétylation et d'une activation du co-activateur transcriptionnel PGCl $\alpha$. Le resvératrol a donc des effets assez proches de ceux observés sous l'effet d'un régime hypocalorique. Y aurait-il avec le resvératrol une potentialité thérapeutique? Cette molécule est présente à l'état naturel, entre autres dans le raisin et le vin rouge et ceci pourrait être relié aux constatations faites il y a plus d'une décennie sur les effets bénéfiques d'une prise régulière de vin dans les maladies cardiovasculaires (appelée the French paradox [4]), ainsi que dans certains cancers et dans les processus inflammatoires et

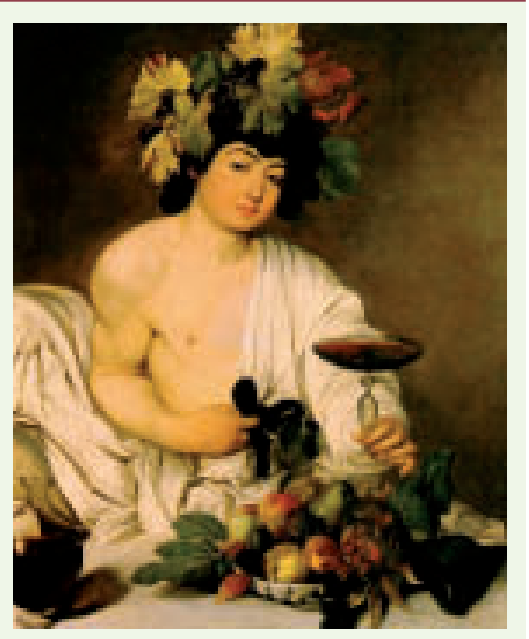

Bacchus, Le Caravage, 1597 (Musée des Offices, Florence).
D. Labie : Département de génétique, développement et pathologie moléculaire, Institut Cochin,

24, rue du Faubourg Saint-Jacques,

75014 Paris, France.

labie@cochin.inserm.fr

P. Ferré : Inserm U671,

Université Pierre et Marie Curie, Paris 6,

Centre Biomédical des Cordeliers,

15, rue de l'źcole de Médecine,

75270 Paris Cedex 06, France.

pferre@bhdc.jussieu.fr

immuns comme le souligne une revue récente [5].

Toutefois, il faut noter que la quantité de resvératrol donnée par jour aux souris correspond chez l'homme à l'absorption de plusieurs centaines de verres de vin! Par ailleurs, le resvératrol possède, outre des activités anti-oxydantes, de nombreux autres effets comme par exemple sur le récepteur des œstrogènes ou le suppresseur de tumeur p53. L'ingestion à long terme de doses élevées de resvératrol se révélera-t-elle aussi efficace chez l'homme que chez la souris, et surtout sans effets secondaires? Alors, en attendant, absorbons du resvératrol sous sa forme liquide la plus appétissante, mais avec beaucoup de modération. $\diamond$

Cheers!

\section{RÉFÉRENCES}

1. Guarente L, Picard F. Calorie restriction: the SIR2 connection. Cell 2005; $120: 473-82$.

2. Baur JA, Pearson KJ, Price NL, et al. Resveratrol improves health and survival of mice on a highcalorie diet. Nature 2006 ; 444 : 337-42.

3. Lagouge M, Argmann C, Gerhart-Hines Z, et al. Resveratrol improves mitochondrial function and protects against metabolic disease by activating SIRTl and PGC-lalpha. Cell 2006; 127 : 1109-22.

4. Renaud W, de Lorgeril, M. Wine, alcohol, platelets, and the French paradox for coronary heart disease. Lancet 1992 ; 339 : 1523-6.

5. Kaeberlein M, Rabinovitch PS. Medicine: grapes versus gluttony. Nature 2006; 444 : 280-1. 